\title{
Isolamento e seleção de fungos filamentosos termorresistentes em etapas do processo produtivo de néctar de maçã
}

\author{
Isolation and selection of heat resistant molds in the production process of apple nectar
}

\author{
Beatriz de Cássia Martins SALOMÃO ${ }^{1}$, Pilar Rodriguez MASSAGUER², Gláucia Maria Falcão ARAGÃO ${ }^{1 *}$
}

\section{Resumo}

Os fungos filamentosos termorresistentes são capazes de sobreviver aos processos de pasteurização aplicados aos produtos de frutas. Este estudo visou isolar e identificar fungos termorresistentes durante o processamento de néctar de maçã ( $\mathrm{pH} 3,4$ e $11,6^{\circ} \mathrm{Brix}$ ), de forma a selecionar o bolor mais termorresistente. $\mathrm{O}$ isolamento foi obtido após choque térmico de $70{ }^{\circ} \mathrm{C} / 2$ horas e incubação a $30^{\circ} \mathrm{C}$ em PDA $(3 \%$ de ágar) acrescido de rosa de bengala. A identificação foi baseada na morfologia e nas estruturas micro e macroscópicas observadas após incubação das cepas em três diferentes meios (G25N, CYA e MEA) e temperaturas. O fungo mais termorresistente foi selecionado pela aplicação de choques térmicos (de $80^{\circ} \mathrm{C} / 20$ minutos até $97^{\circ} \mathrm{C} / 15$ minutos). Foram detectadas 11 linhagens de bolores, sendo 5 termorresistentes. Dentre estas, três cepas, isoladas da matéria-prima e do concentrado de maçã, foram identificadas como Neosartorya fischeri; uma cepa isolada da matéria-prima foi identificada como Byssochlamys fulva, e uma cepa isolada do produto após a primeira pasteurização foi identificada como Eupenicillium sp. As cepas mais resistentes foram as de N. fischeri e B. fulva, que sobreviveram ao tratamento de $95^{\circ} \mathrm{C} / 20$ minutos. Dentre as seis cepas restantes, uma foi identificada como Aspergillus sp., entretanto, nenhuma destas apresentou termorresistência.

Palavras-chave: fungos filamentosos termorresistentes; N. fischeri; B. fulva; néctar de maçã.

\begin{abstract}
Heat resistant molds are able to survive the pasteurization process applied to apple products. This study aimed at detecting and identifying

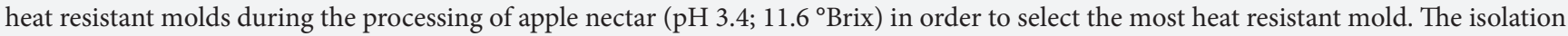
was carried out after heat shock at $70{ }^{\circ} \mathrm{C}$, during 2 hours, and incubation at $30{ }^{\circ} \mathrm{C}$, in PDA ( $3 \%$ agar), where rose bengal was added. The identification of macro and microscopic structures was carried out after incubation in three different media (G25N, CYA, MEA) and temperatures. Different heat shocks, from $80^{\circ} \mathrm{C} / 20$ minutes to $97^{\circ} \mathrm{C} / 15$ minutes, were applied to select the most heat resistant mold. Eleven strains were selected, of which five were heat-resistant: three strains were isolated from apple and concentrated apple juice and were identified as Neosartorya fischeri; one strain, isolated from apple, was identified as Byssochlamys fulva and one strain, isolated from the product after the first pasteurization, was identified as Eupenicillium sp. The most heat-resistant strains belong to $N$. fischeri and B. fulva, which were able to survive at $95^{\circ} \mathrm{C} / 20$ minutes. Among the six remaining, one was identified as Aspergillus sp., however, none of them was heat resistant.

Keywords: heat resistant molds; N. fischeri; B. fulva; apple nectar.
\end{abstract}

\section{Introdução}

Os fungos filamentosos termorresistentes são freqüentemente implicados na deterioração de produtos de frutas processadas, sendo que muitos deles produzem ascósporos que sobrevivem aos tratamentos térmicos, e subseqüentemente, germinam dentro das embalagens, causando grandes perdas econômicas (KOTZEKIDOU, 1997; RAJASHEKHARA; SURESH; ETHIRAJ, 2000). Algumas das alterações causadas nas frutas e derivados são verificadas pelo desenvolvimento de fungos microaerófilos, na parte superior das embalagens, seguido de separação das fases, devido à produção de enzimas pectinolíticas e celulolíticas que alteram a textura do produto (UGWUANYI; OBETA, 1999).

Dentre as espécies termorresistentes repetidamente isoladas de produtos de frutas termicamente processados encontram-se:
Neosartorya fischeri, Byssochlamys fulva, Byssochlamys nivea, Talaromyces flavus e Eupenicillium sp. (RAJASHEKHARA; SURESH; ETHIRAJ, 1996; SILVA; GIBBS, 2004; TOURNAS, 1994; UGWUANYI; OBETA, 1999; VALÍK; PIECKOVÁ, 2001). Os ascósporos destes fungos podem permanecer em estado de dormência em restos de frutas apodrecidas e no solo (RAJASHEKHARA; SURESH; ETHIRAJ, 2000; TOURNAS; TRAXLER, 1994), necessitando ativação térmica para germinarem, o que normalmente corresponde aos processamentos térmicos comerciais aplicados a produtos de frutas (ENIGL; KING Jr.; TOROK, 1993).

Estes microrganismos ainda são conhecidos por produzirem várias micotoxinas, como a patulina, durante seu desenvolvimento nos produtos de frutas, o que representa um grave

Recebido para publicação em 22/9/2006

Aceito para publicação em 18/12/2007 (001858)

${ }^{1}$ Departamento de Engenharia Química e Engenharia de Alimentos, Universidade Federal de Santa Catarina - UFSC, CEP 88040-900, Florianópolis - SC, Brasil

2 Departamento de Ciência de Alimentos, Faculdade de Engenharia de Alimentos da Unicamp - FEA, Universidade Estadual de Campinas - UNICAMP, CEP 13081-970,

Campinas - SP, Brasil

${ }^{*}$ A quem a correspondência deve ser enviada 
problema de saúde pública, uma vez que estes metabólitos secundários podem vir a apresentar potencial carcinogênico e de mutação (PATTERSON, 2005; PIECKOVÁ; JESENSKÁ, 1997).

Maçãs representam um ótimo substrato para o desenvolvimento de bolores termorresistentes e produção de micotoxinas como a patulina (GUMERATO, 1995; SILIHA; ASKAR, 1999). Assim, seu isolamento e identificação nas etapas do processamento de produtos à base de maçã tornam-se importantes para conhecer sua incidência, uma vez que estes são produtos de grande valor comercial, principalmente para os estados de Santa Catarina e Rio Grande do Sul. Além disso, torna-se importante a seleção da cepa mais termorresistente para ser utilizada na determinação dos parâmetros cinéticos de inativação térmica do processamento de produtos de maçã.

Este trabalho teve por objetivos determinar a ocorrência de fungos filamentosos termorresistentes em algumas etapas do processo produtivo de néctar de maçã, bem como selecionar e identificar a cepa mais termorresistente.

\section{Material e métodos}

\subsection{Amostragem}

As amostras descritas a seguir foram obtidas em uma planta de processamento de néctar de maçã (suco de maçã polposo) e acondicionadas em embalagens estéreis de $250 \mathrm{~mL}$. No início da linha de processo, foi retirada uma amostra de 10 unidades de maçãs (variedades Fugi e Gala) e acondicionada em sacos plásticos. Durante o processamento do produto, foi coletada uma amostra de aproximadamente $200 \mathrm{~mL}$ nos seguintes pontos do processo: antes e após a primeira pasteurização, depois do concentrador (concentrado de maçã, $42^{\circ} \mathrm{Brix}$ ), após o resfriamento, antes e após a segunda pasteurização, e produto final. Todas as amostras foram mantidas sob refrigeração até $o$ momento da análise, exceto o produto final, cuja embalagem não necessitava de refrigeração.

\subsection{Isolamento dos fungos termorresistentes}

A matéria-prima, $100 \mathrm{~g}$ da fruta, foi triturada em liqüidificador estéril juntamente com $100 \mathrm{~mL}$ de meio PDA acrescido de $50 \mathrm{mg} . \mathrm{L}^{-1}$ de rosa de bengala (EIROA; AMSTALDEN, 1985). As outras amostras não sofreram preparo prévio. Duzentos mililitros das amostras líquidas foram transferidos para erlenmeyers de $250 \mathrm{~mL}$ e submetidos a choque térmico em banho termostático com agitação (Microquímica MQBMP-01, precisão de $\pm 0,1^{\circ} \mathrm{C}$ ) regulado a $70^{\circ} \mathrm{C}$ por 2 horas, sendo os frascos homogeneizados a cada 10 minutos. Este método de detecção é baseado em Splittistoesser (1976) e Aragão (1989), que sugerem para grandes quantidades de amostras esta combinação de tempo/temperatura, de forma que na primeira hora a temperatura atinja o equilíbrio em todo o produto e o tempo restante seja utilizado para o tratamento térmico que visa destruir as formas termolábeis e ativar os esporos dormentes. Além disso, optouse por esta metodologia, pois ela pode ser utilizada por todas as amostras, independente dos índices de sólidos solúveis das mesmas. Terminado o choque térmico das amostras líquidas, estas foram resfriadas em um banho de gelo e $10 \mathrm{~mL}$ de cada amostra foram plaqueados em profundidade (triplicata) em meio Ágar Batata Dextrose (pH 5,6; MERCK) (PDA) preparado com $3 \%$ de ágar e adicionado de $50 \mathrm{mg} . \mathrm{L}^{-1}$ de rosa de bengala, para evitar o espalhamento das colônias (BAGLIONI; GUMERATO; MASSAGUER, 1999). Após o choque térmico, a amostra da matéria-prima, que foi triturada juntamente com o meio de cultura PDA (como descrito anteriormente), teve seu volume total diretamente distribuído em placas de Petri. Após solidificação nas placas, estas foram envolvidas em um saco plástico (para evitar ressecamento) e incubadas a $30{ }^{\circ} \mathrm{C}$ durante 30 dias, sendo que uma leitura prévia foi realizada no sétimo e décimo dia de incubação. Transcorrido este período, observou-se o desenvolvimento de colônias que foram então isoladas. Para tanto, cada colônia de fungo foi transferida, com o auxílio de uma alça de platina, para placas e tubos inclinados contendo meio PDA (pH 5,6; MERCK).

\subsection{Preparação dos esporos}

O crescimento de cada cepa de fungo deu-se por superfície em garrafas de Roux contendo $180 \mathrm{~mL}$ de Ágar Extrato de Malte (MEA, pH 5,4) e a incubação ocorreu a $30^{\circ} \mathrm{C}$ durante 30 dias. Transcorrido este período, $25 \mathrm{~mL}$ de água destilada estéril foram transferidos para cada garrafa e o crescimento superficial do meio foi "raspado" com o auxílio de pérolas de vidro e bagueta de vidro estéreis (BAGLIONI; GUMERATO; MASSAGUER, 1999). Essa suspensão recém preparada foi filtrada em gaze estéril e submetida a duas centrifugações, cada uma delas a $4000 \mathrm{rpm}$ durante 30 minutos a $5{ }^{\circ} \mathrm{C}$. Após a centrifugação final, foi realizada uma observação microscópica da suspensão, de forma a se certificar da presença dos esporos dos fungos isolados. Todas as suspensões produziram esporos livres, porém a suspensão que seria identificada como $B$. fulva produziu uma mistura de ascos e ascósporos, o que já era esperado para esta espécie (ARAGÃO, 1989). A suspensão final de esporos foi obtida pela adição de água estéril suficiente para atingir concentração próxima a $10^{5}$ esporos $/ \mathrm{mL}$. A quantificação da suspensão final foi feita retirando-se desta uma amostra que foi diluída sucessivamente e plaqueada, por profundidade, em meio PDA (pH 5,6; MERCK) acrescido de $50 \mathrm{mg} . \mathrm{L}^{-1}$ de rosa de bengala. A incubação ocorreu a $30^{\circ} \mathrm{C}$ e a contagem a partir do terceiro dia de incubação. A estocagem da suspensão, até o momento de sua utilização, ocorreu sob refrigeração em frasco contendo pérolas de vidro.

\subsection{Aplicação dos choques térmicos para a seleção do isolado mais termorresistente}

A fim de selecionar o isolado mais termorresistente, as suspensões de esporos preparadas (item 2.3) foram submetidas a diferentes choques térmicos, variando de $80^{\circ} \mathrm{C} / 20$ minutos a $97^{\circ} \mathrm{C} / 15$ minutos, se necessário (BAGLIONI; GUMERATO; MASSAGUER, 1999). A Tabela 1 mostra os diferentes choques térmicos aplicados, conforme necessidade.

Para cada fungo foram utilizados tubos TDT $(8 \times 124 \mathrm{~mm})$ contendo $1,8 \mathrm{~mL}$ de néctar de maçã $\left(11,3^{\circ} \mathrm{Brix}, \mathrm{pH} 3,5\right)$ adicionados de $0,2 \mathrm{~mL}$ da suspensão de esporos ajustados a $10^{5}$ espo- 
ros/mL. Para a aplicação dos choques térmicos, os tubos TDT foram selados com o auxílio de maçarico (oxigênio/gás liquefeito de petróleo), e submersos em um banho termostático com agitação. O início da contagem do tempo do choque ocorreu após a amostra atingir a temperatura estipulada. Para tanto, foi determinado previamente o tempo de elevação em cada temperatura estudada (item 2.5). Após resfriamento em banho de gelo, o conteúdo total de cada tubo $(2 \mathrm{~mL})$ foi transferido para placas de Petri, adicionado de meio PDA (sem a adição de corante) e seguido de homogeneização. As placas foram incubadas a $30^{\circ} \mathrm{C}$ por até 7 dias. $\mathrm{O}$ crescimento do fungo, após este período, foi um indicativo de resistência ao choque térmico.

\subsection{Determinação do tempo de elevação da temperatura}

Tubos TDT $(8 \times 124 \mathrm{~mm})$ foram preenchidos com $2 \mathrm{~mL}$ de néctar de maçã e inseridos de um termopar tipo T de cobreconstantan. Assim que o banho termostático atingiu as temperaturas selecionadas $\left(80,85,92,95\right.$ e $\left.97^{\circ} \mathrm{C}\right)$, o tubo contendo o termopar foi colocado no banho e o cronômetro acionado. Quando a amostra atingiu a temperatura selecionada, registrouse o tempo marcado pelo cronômetro (tempo de elevação).

\subsection{Identificação}

A identificação foi realizada a partir das observações macroscópicas e microscópicas das características e estruturas dos fungos filamentosos isolados, seguindo a chave de identificação proposta por Pitt e Hocking (1985). A análise macroscópica foi baseada nas descrições das colônias nos meios Ágar Czapeck Extrato de Levedura (CYA), Ágar Extrato de Malte (MEA) e Ágar Glicerol Nitrato 25\% (G25N) (PITT; HOCKING, 1985). Para a inoculação do fungo nas placas contendo os meios, tomou-se um fragmento deste (com o auxílio de uma alça de platina) que foi introduzido no centro da placa. Antes da incubação, as placas foram envolvidas por um saco plástico. De acordo com a recomendação das chaves de identificação (PITT; HOCKING, 1985), os isolados inoculados nos três meios (CYA, G25N e MEA) foram incubados a $25^{\circ} \mathrm{C}$ e aqueles em meio CYA foram incubados a 5,25 e $37^{\circ} \mathrm{C}$. Entretanto, foram realizadas incubações adicionais em $\mathrm{G} 25 \mathrm{~N}$ a 5 e $37^{\circ} \mathrm{C}$, e também em PDA e MEA a $30^{\circ} \mathrm{C}$, de forma a auxiliar o processo de identificação (TOURNAS, 1994). Após 7 dias de incubação, foram realizadas as análises macroscópicas que consistiram na medição do diâmetro das colônias e na verificação de suas colorações e características. Pela microscopia (em lâmina corada com lactofucsina) foi observada a presença e as características

Tabela 1. Choques térmicos aplicados (tempo/temperatura) aos esporos das cepas isoladas.

\begin{tabular}{cc}
\hline Temperatura $\left({ }^{\circ} \mathrm{C}\right)$ & Tempo (minutos) \\
\hline 80 & 20 \\
85 & 15 \\
92 & 10 \\
95 & 10 \\
95 & 20 \\
97 & 15 \\
\hline
\end{tabular}

dos ascocarpos, ascos e ascósporos; além da identificação da fase anamorfa (assexuada).

\section{Resultados e discussão}

\subsection{Isolamento das cepas de fungos}

Foram isoladas onze cepas de bolores. Dentre estas cepas, três foram identificadas como sendo de N. fischeri, uma de B. fulva, uma de Eupenicillium sp., uma de Aspergillus sp. (a qual apresentou somente fase imperfeita) e cinco não identificadas (consideradas não termorresistentes por não resistirem aos tratamentos térmicos superiores a $80^{\circ} \mathrm{C} / 20$ minutos).

Na Tabela 2 são apresentados os fungos isolados e sua origem no processo.

Verificou-se, pela análise dos resultados, que N. fischeri foi o fungo de maior incidência dentre os isolados termorresistentes. Gumerato (1995) também isolou esta espécie em estudo realizado com purê de maçãs. No presente estudo, a espécie N. fischeri foi isolada na matéria-prima e no concentrado de maçã, sendo que este último sofreu os efeitos térmicos da pasteurização e da concentração, o que demonstra sua grande termorresistência. Além disso, o fungo $N$. fischeri é um potencial produtor de micotoxinas como as fumitremorginas (A, B, C) e a verruculogena (NIELSEN, 1991; SURESH; ETHIRAJ; JAYARAM, 1996; TOURNAS, 1994).

Na matéria-prima foram encontradas as duas espécies reportadas pela literatura como as mais termorresistentes (N. fischeri e B. fulva), indicando que estes bolores são introduzidos no processo a partir das maçãs in natura. Durante a visita à empresa, observou-se que muitas maçãs utilizadas estavam apodrecidas e que a etapa de seleção não foi suficiente para eliminá-las. Tais frutas são certamente responsáveis pela entrada de fungos na planta de processamento. Essas maçãs de qualidade ruim são aquelas geralmente recolhidas no chão e próximas das árvores, o que causa grande contaminação por

Tabela 2. Cepas de fungos filamentosos termorresistentes isoladas no processo produtivo de néctar de maçã.

\begin{tabular}{|c|c|}
\hline Origem & Isolado \\
\hline \multirow{2}{*}{ Matéria-prima (MP) } & Neosartorya fischeri \\
\hline & Byssochlamys fulva \\
\hline $\begin{array}{l}\text { Produto antes da pasteurização } 1 \\
\text { (PA1) }\end{array}$ & FNTNI $^{*}$ \\
\hline Produto depois da & Eupenicillium sp. \\
\hline pasteurização 1 (PP1) & FNTNI* \\
\hline $\begin{array}{l}\text { Produto depois do } \\
\text { concentrador (PC) }\end{array}$ & Neosartorya fischeri \\
\hline Produto resfriado (PR) & FNTNI $^{*}$ \\
\hline $\begin{array}{l}\text { Produto antes da } \\
\text { pasteurização } 2 \text { (PA2) }\end{array}$ & FNTNI* \\
\hline $\begin{array}{l}\text { Produto depois da } \\
\text { pasteurização } 2 \text { (PA2) }\end{array}$ & Nenhum isolamento \\
\hline \multirow[t]{2}{*}{ Produto final (PF) } & Aspergillus spp. \\
\hline & FNTNI $^{*}$ \\
\hline
\end{tabular}

${ }^{\star}$ FNTNI: Fungo não termorresistente não identificado. 
fungos originários do solo. Além disso, é prática comum das empresas retirar as maçãs do estoque refrigerado e colocálas em local aberto até o processamento. Um período maior de permanência destas frutas à temperatura e umidade não controlada pode ser crítico por permitir o desenvolvimento de fungos deteriorantes e toxigênicos (MORALES et al., 2007; MORALES et al., 2007). Portanto, constata-se que deve ser utilizada a matéria-prima não apodrecida ou lesionada e devese controlar o tempo de exposição das frutas à temperatura ambiente, além de ser recomendável uma rigorosa seleção e sanitização dos frutos (MORALES et al., 2007; MORALES et al., 2007; SPLITTSTOESSER, 1976).

Pela Tabela 2 nota-se ainda que a espécie $B$. fulva, que foi isolada na matéria-prima, não aparece nas demais etapas. Isto pode ter ocorrido devido ao tipo de amostragem e/ou à baixa incidência deste fungo. Além disso, o não isolamento do fungo $N$. fischeri na etapa da primeira pasteurização pode ser decorrente também da dificuldade de amostragem. Entretanto, cabe ressaltar a importância deste resultado para a indústria de suco de maçã, uma vez que estes fungos podem ser facilmente introduzidos no processo, e devido à sua alta termorresistência, resistirem à pasteurização do suco levando à sua sobrevivência e conseqüente desenvolvimento no produto final.

Deve-se ressaltar que o gênero Byssochlamys é reconhecidamente um potencial produtor de patulina em maçãs apodrecidas. Essa toxina apresenta resistência ao calor, principalmente em meios ácidos, como é o caso do suco de maçã. Assim, o risco da presença de Byssochlamys na fruta significa o risco de transferência de patulina para o produto final, gerando um grave problema de saúde aos consumidores, uma vez que esta micotoxina tem revelado grande espectro de atividade e pode ser um agente carcinogênico e de mutação (SILIHA; ASKAR, 1999). A contagem do número de cepas, por etapa do processamento, forneceu uma visão clara do grau de contaminação do néctar de maçã nas diferentes etapas de fabricação. Nas etapas finais do processamento é notada a ausência de fungos termorresistentes, mostrando que uma seqüência de tratamentos térmicos e/ou a baixa incidência pode ter provocado injúria suficiente para a destruição destes bolores.

\subsection{Seleção dos isolados mais termorresistentes}

A importância dos tratamentos térmicos na destruição de fungos termorresistentes torna relevante a busca por um isolado de maior termorresistência, para que a partir dele, parâmetros cinéticos sejam obtidos e usados para assegurar a inocuidade do produto final. Na Tabela 3 estão apresentados os fungos isolados do processo produtivo e seus limites de sobrevivência aos choques térmicos. Por esta tabela, pode-se verificar que todas as espécies identificadas como fungos termorresistentes confirmaram esta característica sobrevivendo ao choque inicial de $80{ }^{\circ} \mathrm{C} / 20$ minutos (BAGLIONI; GUMERATO; MASSAGUER, $1999)$ e ao choque $\left(85^{\circ} \mathrm{C} / 30\right.$ segundos) (BEUCHAT; PITT, 1992). As demais não foram consideradas termorresistentes. $O$ isolamento de culturas termolábeis, após a etapa de concentração, inclusive no produto final, sugere uma recontaminação por via aérea, por equipamentos ou através das embalagens.
Tabela 3. Limites de sobrevivência de todas as espécies isoladas no processamento de néctar de maçã de acordo com sua origem no processo.

\begin{tabular}{|c|c|c|}
\hline Origem no processo & Identificação & Sobrevivência até \\
\hline Matéria-prima (MP) & $\begin{array}{l}\text { N. fischeri } \\
\text { B. fulva }\end{array}$ & $\begin{array}{l}92^{\circ} \mathrm{C} / 10 \text { minutos } \\
95^{\circ} \mathrm{C} / 20 \text { minutos }\end{array}$ \\
\hline $\begin{array}{l}\text { Produto antes da } \\
\text { pasteurização } 1 \text { (PA1) }\end{array}$ & (não identificado) & $<80^{\circ} \mathrm{C} / 20$ minutos \\
\hline $\begin{array}{l}\text { Produto depois da } \\
\text { pasteurização } 1 \text { (PP1) }\end{array}$ & $\begin{array}{l}\text { Eupenicillium sp. } \\
\text { (não identificado) }\end{array}$ & $\begin{array}{l}85^{\circ} \mathrm{C} / 15 \text { minutos } \\
<80^{\circ} \mathrm{C} / 20 \text { minutos }\end{array}$ \\
\hline $\begin{array}{l}\text { Produto depois do } \\
\text { concentrador (PC) }\end{array}$ & $\begin{array}{l}\text { N. fischeri } \\
\text { N. fischeri }\end{array}$ & $\begin{array}{l}95^{\circ} \mathrm{C} / 20 \text { minutos } \\
95^{\circ} \mathrm{C} / 20 \text { minutos }\end{array}$ \\
\hline Produto resfriado (PR) & (não identificado) & $<80^{\circ} \mathrm{C} / 20$ minutos \\
\hline $\begin{array}{l}\text { Produto antes da } \\
\text { pasteurização } 2 \text { (PA2) }\end{array}$ & (não identificado) & $<80^{\circ} \mathrm{C} / 20$ minutos \\
\hline Produto final (PF) & $\begin{array}{l}\text { Aspergillus sp. } \\
\text { (não identificado) }\end{array}$ & $\begin{array}{l}<80^{\circ} \mathrm{C} / 20 \text { minutos } \\
<80^{\circ} \mathrm{C} / 20 \text { minutos }\end{array}$ \\
\hline
\end{tabular}

A cepa de B. fulva isolada da matéria-prima e as duas cepas de $N$. fischeri isoladas do produto concentrado sobreviveram ao choque térmico de $95^{\circ} \mathrm{C} / 20$ minutos (Tabela 3 ) e, portanto, podem ser consideradas as mais termorresistentes. N. fischeri também foi a cepa mais termorresistente isolada por Baglioni, Gumerato e Massaguer (1999) a partir de um processamento asséptico de polpa de tomate. As cepas de N. fischeri isoladas no concentrado de maçã são ainda consideradas de maior importância comercial, pois este produto é usado como base para diversos outros, inclusive alimentos para bebês e, portanto, a presença de um fungo toxigênico pode trazer risco à saúde dos consumidores, principalmente das crianças.

Dentre os critérios de identificação propostos por Pitt e Hocking (1985) está a determinação do diâmetro das colônias. A Tabela 4 apresenta uma comparação entre os resultados das medidas de diâmetro de colônia verificados por estes autores e os resultados encontrados neste estudo.

É importante ressaltar que as características gerais das colônias como: coloração da parte superior e inferior, formação ou não de grumos, septação, densidade do micélio, flocosidade, entre outros (dados não mostrados), também auxiliaram na identificação dos isolados. A Figura 1 apresenta imagens de algumas estruturas microscópicas dos fungos termorresistentes que auxiliaram no processo de identificação.

\section{Conclusões}

Neosartorya fischeri e Byssochlamys sp. são considerados os fungos de maior termorresistência dentre os contaminantes de frutas e, neste estudo, foram isolados na matéria-prima demonstrando que a maçã pode introduzir estes bolores na planta de processamento. Assim, conclui-se que a utilização de frutas sadias e íntegras é uma das exigências para melhoria da qualidade do produto. Verificou-se que, dentre as etapas do processo, a primeira pasteurização (PP1) não foi eficaz o suficiente para a eliminação de formas termorresistentes, uma vez que o gênero Eupenicillium sp. foi ali isolado.

Neosartorya fischeri foi selecionado como o fungo mais termorresistente e de maior importância comercial, uma vez que 
Tabela 4. Diâmetro médio das colônias desenvolvidas pelas espécies isoladas, após 7 dias de incubação nos meios de cultura e temperaturas de crescimento.

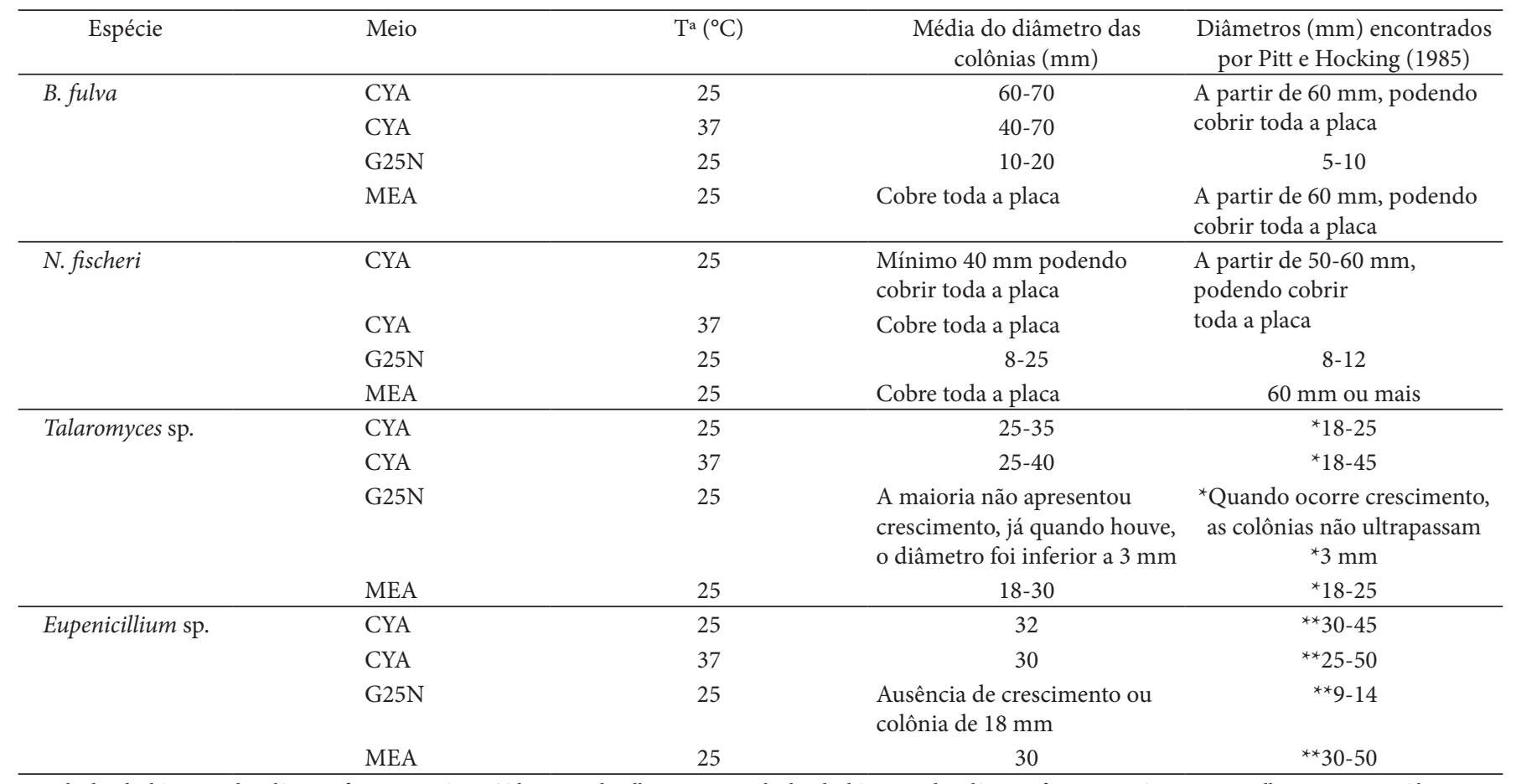

${ }^{\star}$ Resultados de diâmetros de colônias referentes ao gênero Talaromyces bacillisporus; ${ }^{*}$ Resultados de diâmetros de colônias referentes ao gênero Eupenicillium javanicum. Observação: Não foi verificado crescimento a $5^{\circ} \mathrm{C}$.
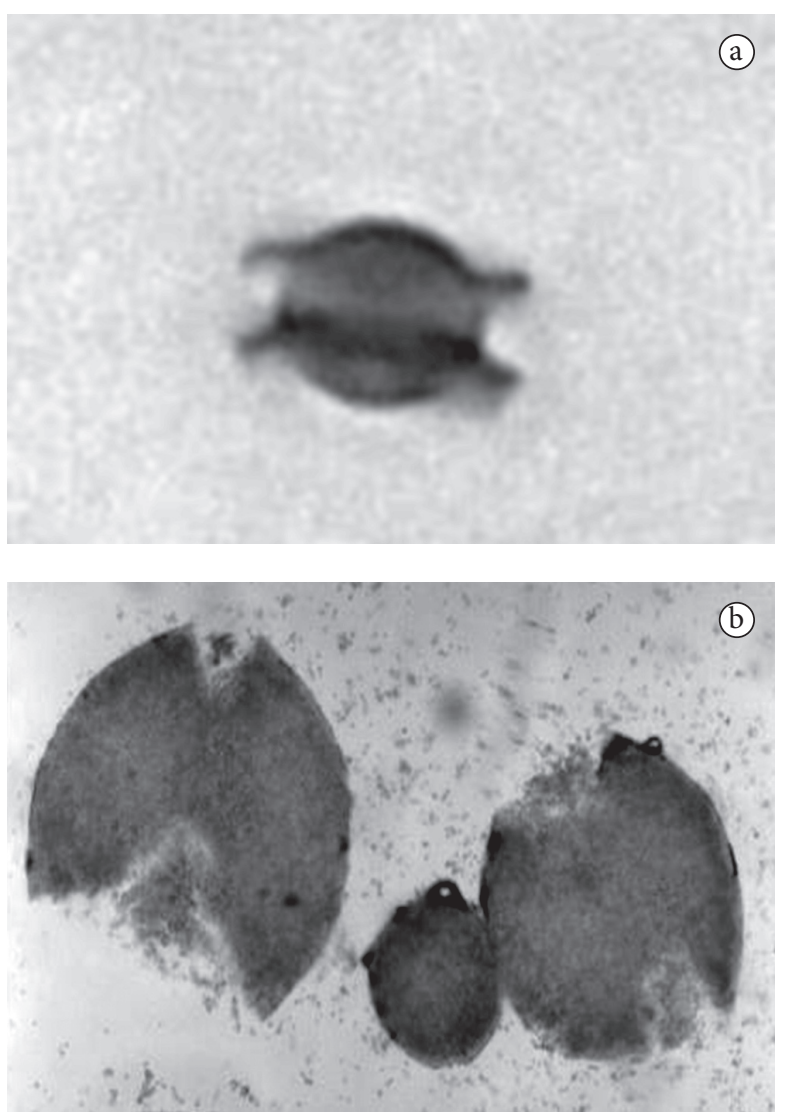
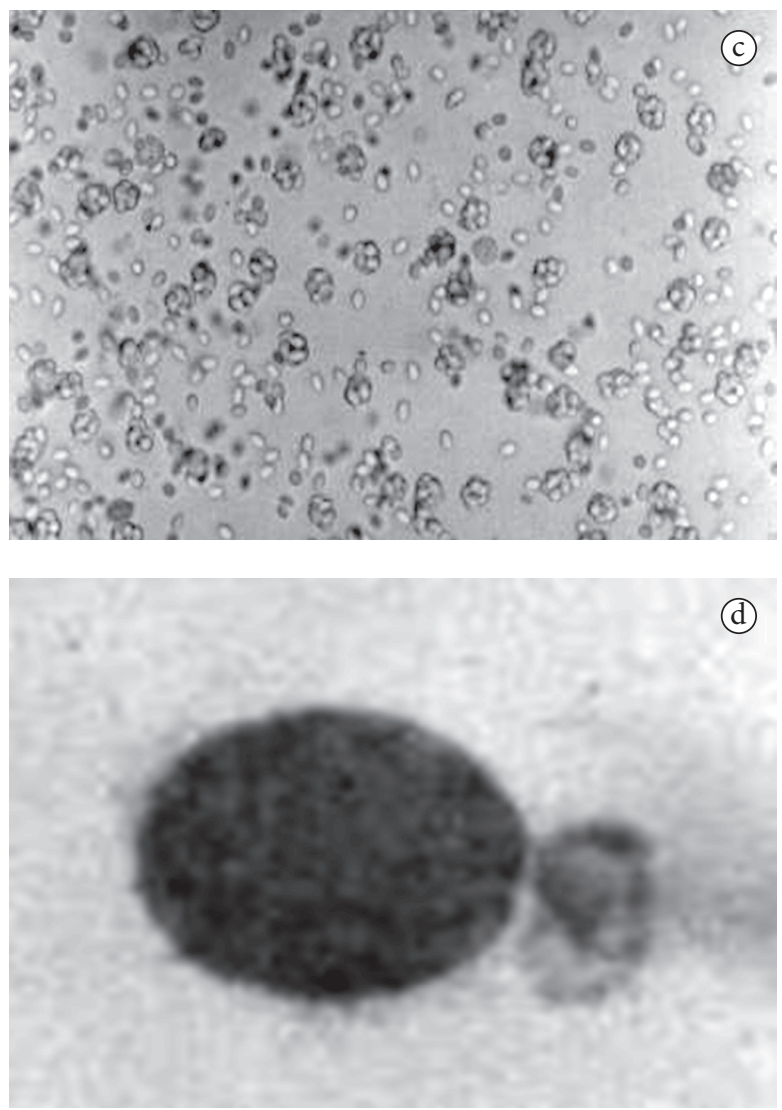

Figura 1. Imagens de algumas estruturas microscópicas dos fungos filamentosos termorresistentes observadas em microscópio Olympus modelo CH 40, ocular de 10x e coloração com Lactofucsina; a) Ascósporo; b) Cleistotécio de Neosartorya fischeri observados com objetiva de 100x e 10x, respectivamente; c) Ascos e ascósporos de Byssochlamys fulva observados com objetiva 40x; e d) Cleistotécio de Eupenicillium sp. observado com objetiva de 10x. 
foi isolado do concentrado de maçã e sobreviveu ao choque térmico de $95{ }^{\circ} \mathrm{C} / 20$ minutos, cujo binômio (tempo/temperatura) é bastante superior aos tratamentos de pasteurização aplicados a produtos de maçã $\left(95^{\circ} \mathrm{C} / 30\right.$ segundos).

A melhoria na qualidade da matéria-prima e do processo de estocagem, seleção e sanificação das maçãs in natura promoveriam certamente a diminuição da carga microbiana introduzida no processo produtivo do suco. Além disso, tendo-se em vista que fungos não resistentes foram isolados em algumas etapas do processo, inclusive no produto final, deve-se investir em melhores condições higiênicas nas áreas de processamento e envase para garantir o controle dos fungos não termorresistentes e também daqueles termorresistentes, uma vez que a contaminação cruzada pode permitir sua disseminação.

\section{Referências bibliográficas}

ARAGÃO, G. M. F. Identificação e determinação da resistência térmica de fungos filamentosos termo-resistentes isolados da polpa de morango. Campinas, 1989, 139p. Dissertação (Mestrado em Engenharia de Alimentos) - Faculdade de Engenharia de Alimentos, Universidade Estadual de Campinas (UNICAMP).

BAGLIONI, F.; GUMERATO, H. F.; MASSAGUER, P. R. Ocorrência de fungos filamentosos termo-resistentes em polpa de tomate envasada assepticamente. Ciênc. Tecnol. Aliment., Campinas, v. 19, n. 2, p. 258-263, 1999.

BEUCHAT, L. R.; PITT, J. I. Detection and enumeration of heat resistant molds. In: VANDERZANT, C.; SPLITTSTOESSER, D.F. (Eds.).Compendium of Methods for the Microbiological Examination of Foods. 3. ed. Washington: A.P.H.A., 1992. Cap. 17, p. 251-263.

EIROA, G.; AMSTALDEN, V. C. Ocorrência de espécies de Byssochlamys em hortas, pomares e vinhedos da região de Campinas. Col. ITAL, Campinas, v. 15, n. 1, p. 61-70, 1985.

ENIGL, D. C.; KING Jr., A. D.; TOROK, T. Talaromyces trachyspermus, a heat resistant mold isolated from fruit juice. J. Food Prot., Des Moines, v. 56, n. 12, p. 1039-1042, 1993.

GUMERATO, H. F. Desenvolvimento de um programa de computador para identificação de alguns fungos comuns em alimentos e determinação da resistência térmica de Neosartorya fischeri isolado de maçãs. Campinas, 1995. 98p. Dissertação (Mestrado em Engenharia de Alimentos) - Faculdade de Engenharia de Alimentos, Universidade Estadual de Campinas (UNICAMP).

KOTZEKIDOU, P. Heat resistance of Byssochlamys nivea, Byssochlamys fulva and Neosartorya fischeri isolated from canned tomato paste. J. Food Sci., Chicago, v. 62, n. 2, p. 410-412/437, 1997.

MORALES, $\mathrm{H}$. et al. Cold and ambient deck storage prior to processing as a critical control point for patulin accumulation. Int. J. Food Microb., Amsterdam, v. 116, n. 2, p. 260-265, 2007.
MORALES, H. et al. Patulin accumulation in apples by Penicillium expansum during postharvest stages. Let. Appl. Microb., Oxford, v. 44, n. 1, p. 30-35, 2007.

NIELSEN, P. V. Preservative and temperature effect on growth of three varieties of the heat-resistant mould, Neosartorya fischeri, as measured by an impedimetric method. J. Food Sci., Chicago, v. 56, n. 6, p. 1735-1740, 1991

PATTERSON, M. F. A Review. Microbiology of pressure treated foods. J. Appl. Microbiol., Oxford, v. 98, n. 6, p. 1400-1409, 2005.

PIECKOVÁ, E.; JESENSKÁ, Z. Toxinogenicity of heat-resistant fungi detected by a bio-assay. Int. J. Food Microbiol., Amsterdam, v. 36, n. 2-3, p. 227-229, 1997.

PITT, J. I.; HOCKING, A. D. Fungi and Food Spoilage. Sydney: Academic Press, 1985.

RAJASHEKHARA, E.; SURESH, E. R.; ETHIRAJ, S. Influence of different heating media on thermal resistance of Neosartorya fischeri isolated from papaya fruit. J. Appl. Bacteriol., Oxford, v. 81, n. 3, p. 337-340, 1996.

. Modulation of thermal resistance of ascospores of Neosartorya fischeri by acidulants and preservatives in mango and grape fruit. J. Food Microbiol., Illinois, v. 17, n. 3, p. 269-275, 2000.

SILIHA, H.; ASKAR, A. Patulin in apple juice and children's apple food. Fruit processing, Strabenhaus, v. 5, n. 3, p. 164-167, 1999.

SILVA, F. V. M.; GIBBS, P. Target selection in designing pasteurization processes for shelf-stable high-acid fruit products. Crit Rev Food Sci Nutr., Boca Raton, v. 44, n. 5, p. 353-360, 2004.

SPLITTSTOESSER, D. F. Enumeration of heat resistant mold (Byssochlamys). In: Compendium of methods for the Microbiology. Washington: Exam. of Foods. Am. Public. Health Assoc., 1976. p. 230-234.

SURESH, E. R.; ETHIRAJ, S.; JAYARAM, H. L. Heat resistance of Neosartorya fischeri isolated from grapes. J. Food Sci. Technol., New York, v. 33, n. 1, p. 76-77, 1996.

TOURNAS, V. Heat resistant fungi of importance to the food and beverage industry. Crit. Rev. Microbiol, Boca Raton, v. 20, n. 4, p. 243-263, 1994.

TOURNAS, V.; TRAXLER, R. W. Heat resistance of a Neosartorya fischeri strain isolated from pineapple juice frozen concentrate. J. Food Prot., Des Moines, v. 57, n. 9, p. 814-816, 1994.

UGWUANYI, J. O.; OBETA, J. A. N. Pectinolytic and cellulolytic activities of heat resistant fungi and their macerating effects on mango and African mango. J. Sci. Food Agric., Sussex, v. 79, n. 7, p. 1054-1059, 1999.

VALÍK, L.; PIECKOVÁ, E. Growth modelling of heat-resistant fungi: the effect of water activity. Int. J. Food Microbiol., Amsterdam, v. 63 , n. 1-2, p. 11-17, 2001. 